\title{
(6) OPEN ACCESS \\ Inequity of access to ACE inhibitors in Swedish heart failure patients: a register-based study
}

\author{
Anna Ohlsson, ${ }^{1}$ Bertil Lindahl, ${ }^{2}$ Marianne Hanning, ${ }^{1,3}$ Ragnar Westerling ${ }^{1}$
}

${ }^{1}$ Department of Public Health and Caring Sciences, Uppsala University, Uppsala, Sweden ${ }^{2}$ Department of Medical Sciences, Uppsala Clinical Research Center, Uppsala University, Uppsala, Sweden ${ }^{3}$ National Board of Health and Welfare, Stockholm, Sweden

\section{Correspondence to}

Dr Anna Ohlsson,

Department of Public Health and Caring Sciences, Uppsala University, Box 564, Uppsala 751 22, Sweden:

anna.ohlsson@pubcare.uu.se

Received 12 March 2015 Revised 25 May 2015

Accepted 20 June 2015 Published Online First 10 August 2015

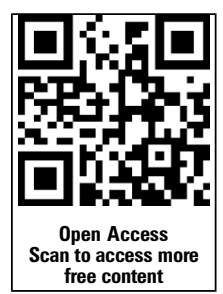

CrossMark

To cite: Ohlsson $A$, Lindahl $B$, Hanning $M$, et al. J Epidemiol Community Health 2016;70:97-103.
ABSTRACT
Background Several international studies suggest inequity in access to evidence-based heart failure (HF) care. Specifically, studies of ACE inhibitors (ACEIs) point to reduced ACEl access related to female sex, old age and socioeconomic position. Thus far, most studies have either been rather small, lacking diagnostic data, or lacking the possibility to account for several individualbased sociodemographic factors. Our aim was to investigate differences, which could reflect inequity in access to ACEls based on sex, age, socioeconomic status or immigration status in Swedish patients with HF. Methods Individually linked register data for all Swedish adults hospitalised for HF in 2005-2010 ( $n=93258$ ) were analysed by multivariate regression models to assess the independent risk of female sex, high age, low employment status, low income level, low educational level or foreign country of birth, associated with lack of an ACEI dispensation within 1 year of hospitalisation. Adjustment for possible confounding was made for age, comorbidity, Angiotensin receptor blocker therapy, period and follow-up time.

Results Analysis revealed an adjusted OR for no ACEI dispensation for women of $1.31(95 \% \mathrm{Cl} 1.27$ to 1.35$)$; for the oldest patients of $2.71(95 \% \mathrm{Cl} 2.53$ to 2.91$)$; and for unemployed patients of $1.59(95 \% \mathrm{Cl} 1.46$ to 1.73).

Conclusions Access to ACEl treatment was reduced in women, older patients and unemployed patients. We conclude that access to ACEls is inequitable among Swedish patients with HF. Future studies should include clinical data, as well as mortality outcomes in different groups.

\section{INTRODUCTION}

Heart failure (HF) is an important cause of morbidity and mortality worldwide. In Sweden, the prevalence of HF is around 2\%, the incidence 3.8/1000 person-years, and the mortality rate $3.1 / 1000$ person-years. Age-adjusted HF mortality is higher $(\mathrm{HR}=1.29)$ in men than in women. ${ }^{12}$

Renin-angiotensin system (RAS) blockade with ACE inhibitors (ACEIs) reduces mortality and morbidity from $\mathrm{HF}$ with reduced ejection fraction (HF-REF). ${ }^{3-5}$ In HF with preserved ejection fraction (HF-PEF), the role of ACEIs is unclear. $^{6}$ RAS blockade is a cornerstone in HF therapy, and ACEIs are recommended as base treatment in clinical guidelines worldwide. Angiotensin receptor blockers (ARBs) are alternative RAS-blocking drugs in case of ACEI intolerance. ${ }^{7}$ However, not all patients with HF have access to RAS blockade. Prescription of ACEIs is 54-62\% in European surveys of pharmacotherapy in $\mathrm{HF}^{8}{ }^{8}$ Similar results have been found in Sweden. ${ }^{10} 11$

Low-socioeconomic position is a strong predictor for developing HF. ${ }^{12}{ }^{13}$ Furthermore, sex and age inequity in ACEI treatment of $\mathrm{HF}$ has been suggested. ${ }^{8} 101415$ ACEI treatment for other diagnoses follows a similar pattern in which women, ${ }^{16} 17$ socioeconomically deprived persons ${ }^{18}$ and immigrants/ethnic minorities ${ }^{19}{ }^{20}$ are undertreated. These findings suggest inequity in HF treatment and access to ACEIs, based on sex, age, socioeconomic factors and immigration status.

The Swedish health and medical services act states that the goal for healthcare and medical services is good health and equal healthcare for all of the population. Hence, investigating the attainment of this goal is warranted to enhance every patient's access to the best available medical care.

To the best of our knowledge, no previous study of ACEI access in HF had the combined advantages of total national coverage of HF hospitalisations, individual-level sociodemographic data, ARB use and comorbidities. This study aimed to investigate differences in access to ACEIs based on sex, age, socioeconomic status or immigration status in Swedish adults hospitalised for HF during 20052010. We hypothesised that female sex, old age, foreign country of birth, low education, unemployment or low income is associated with a risk of not being dispensed ACEI within 1 year of being hospitalised for HF.

\section{METHODS}

Materials

Data from registers at the Swedish National Board of Health and Welfare and Statistics Sweden were linked by personal identifiers. The Swedish National Patient Register (NPR) ${ }^{21}$ contains individual data for all inpatient hospital discharges in Sweden since 1987. These data include primary and additional diagnoses and admission and discharge dates. More than $99 \%$ of hospital stays are registered, and the overall validity is $85-95 \% .^{22}$ The validity for HF diagnosis is $95 \%$ when registered as primary diagnosis. ${ }^{23}$

The Swedish Prescribed Drug Register 2425 holds records of all dispensed drugs in Sweden since 1999, and since July 2005 with personal identifiers. For drug dispensations, the registration is complete (although demographic data are missing in $0.02-0.6 \%$ of cases). The register has been described previously. ${ }^{25}$ The Longitudinal Integration Database for Health Insurance and Labour Market Studies (LISA by Swedish acronym $)^{26}$ combines information from several sociodemographic population registers. Variables 
include country of birth, educational level, occupational status and income level. All Swedish citizens older than 16 years residing in Sweden on 31 December are registered yearly. Some variables are missing for certain individuals, the extent of which varies for different variables.

\section{Data}

Study population

The study population was defined as all persons $\geq 20$ years old, hospitalised with HF as primary diagnosis 2005-2010, as recorded in NPR $(n=93258)$. The International Classification of Diseases (ICD-10) codes I11.0, I13.0, I13.2, I42.0, I42.3I42.9, I50.0, I50.1 and I50.9 were selected. Cases of HF registered as secondary diagnosis were excluded because the validity was considered too low based on previous research. ${ }^{23}$ Data from NPR were merged, using personal identifiers, with records of drug dispensations, as well as sociodemographic variables. The first hospitalisation after 1 July 2005 was chosen for analysis for each individual.

\section{Definitions and categorisations}

Category definitions for the variables are listed in table 1, along with characteristics of the study population.

Income was converted from Swedish currency (SEK) to Euros ${ }^{i}$. The variable country/region of birth was provided from Statistic Sweden in 10 geographical groups, but was recategorised because original groups were small. Employment was categorised according to statistics Sweden's classes, based on the existence of a statement of income, as well as the level of income as follows:

- Gainful employment: Income statement in November of registered year+a yearly income of at least approximately $€ 5000$ for men, and $€ 4500$ for women (aged 25-54, level for years 2004-2005; level varies somewhat with year and age group).

- Sporadic gainful employment: No income statement in November of registered year. Some income during the year, but not enough to be classified as continuously employed.

- No gainful employment: No income statement at all during registered year. All persons over 84 years old are automatically placed in this category.

\section{Confounding \\ Comorbidity}

Comorbidity data were retrieved from NPR. The diagnoses that could affect the probability of receiving an ACEI and were included in the analyses are: hypertension (ICD-10: I10, I.11.9, I12, I13.1, I13.9, I15); acute or previous myocardial infarction (MI) (I21, I22, I23, I25.2); kidney failure (N17, N18, N19, I13.1, I12.0); diabetes mellitus (DM) (E10, E11, E12, E13, E14); and dementia (G30, G31.0, G31.2, G31.3, G31.4, G31.5, G31.6, G31.7, G31.8). DM was also captured by records of dispensed diabetes drugs as the diagnosis is likely to be underestimated in the NPR. ${ }^{22}$

\section{Alternative treatment}

ARB therapy can replace ACEIs. Therefore, we included a variable for receiving an $\mathrm{ARB}$ within 1 year of HF hospitalisation.

${ }^{\mathrm{i}}$ Based on the exchange rate on $03 / 04 / 14$ of the Swedish Central bank ("Riksbanken") (http://www.riksbank.se/en/Interest-and-exchange-rates/).

\section{Time period}

The time period may affect the chance of receiving ACEIs, as there was increasing focus on equity in healthcare during the studied period. Hence, a variable for year of HF hospitalisation was created.

\section{Follow-up time}

Some patients with HF die within 1 year of hospitalisation. This could cause confounding because outcome was defined as being dispensed an ACEI within 1 year of hospitalisation. A short follow-up time would risk underestimating access to ACEIs for patients who were prescribed an ACEI, but did not survive long enough to have the prescription dispensed.

\section{Statistical analysis}

Comparisons of ACEI dispensation between groups were tested by the $\chi^{2}$ statistic. Significant associations were included in stepwise multivariate logistic regression analysis to further assess the relation between sociodemographic covariates and dispensation of an ACEI. Adjustment was made for possible confounding (ie, $\mathrm{ARB}$ dispensation, year and follow-up time). The dependent (outcome) variable was 'lack of ACEI dispensation at least one time within 1 year of the index date'. Explanatory covariates were sex, country/region of birth, age class, educational level, employment status and income class. The significance level was set at $\mathrm{p}<0.05$. The first model produced crude ORs for the effect on ACEI dispensation of all of the hypothesised explanatory covariates separately (model 1). The second model was adjusted for age (model 2). In model 3, age, comorbidity, ARB use, year and follow-up time were added. Finally, all confounding and explanatory covariates were entered in model 4. An age-stratified multivariable logistic regression was also performed, with adjustment for comorbidity, ARB use, year and follow-up time. The explanatory covariates entered were: sex, country/region of birth, educational level, employment status and income class.

\section{Ethical considerations}

The study conforms to the Helsinki declaration. Owing to the study design, it was not feasible to obtain informed consent. The study was approved by the Swedish Central Ethical Review Board (Dnr Ö 29-2011), and the linking of data was subjected to ethical vetting at the Swedish National Board of Health and Welfare and Statistics Sweden.

\section{RESULTS}

\section{Baseline characteristics}

The number of patients was 93258 , of which $47.8 \%$ were women (table 1). For each variable, the number in that particular analysis is stated in the tables to disclose the degree of missing data. The mean age was 79.2 years, and women were older than men. Mean \pm SD follow-up time was $252 \pm 145$ days. The majority of participants were Swedish born (88.5\%). Half of the patients had less than 9 years of education and less than $6 \%$ were in the highest education group. Men were twice as likely as women to have $\geq 3$ years of upper secondary school. Most of the study subjects $(86.6 \%)$ had no gainful employment, with a higher proportion in women $(93 \%)$ than in men $(80.6 \%$ $\mathrm{p}<0.001)$. Mean yearly income was $€ 17412$ and women's mean income was lower than men's $(p<0.001)$. One-third of the men were in the highest income class compared with $13.7 \%$ of the women. 
Table 1 Baseline characteristics

\begin{tabular}{|c|c|c|c|c|c|}
\hline \multirow[b]{2}{*}{ Characteristic } & \multirow[b]{2}{*}{ Mean/median } & \multirow{2}{*}{$\begin{array}{l}\text { Number } \\
n=93258\end{array}$} & \multirow[b]{2}{*}{$(\%)$} & \multicolumn{2}{|l|}{ Distribution (\%) } \\
\hline & & & & Women: $n=44619$ & Men: $n=48639$ \\
\hline Mean age (SD) & $79.2(11.14)$ & & & $81.7(10.2)$ & $76.9(11.5)$ \\
\hline \multicolumn{6}{|l|}{ Age class (years) } \\
\hline $20-64$ & & 10045 & 10.8 & 6.6 & 14.6 \\
\hline $65-74$ & & 14853 & 15.9 & 11.9 & 19.6 \\
\hline $75-84$ & & 34115 & 36.6 & 35.2 & 37.8 \\
\hline$\geq 85$ & & 34245 & 36.7 & 46.3 & 27.9 \\
\hline Country/region of birth $n=93243$ & & & & $n=44610$ & $\mathrm{n}=48633$ \\
\hline Sweden & & 82497 & 88.5 & 87.8 & 89.1 \\
\hline Nordic country & & 4744 & 5.1 & 5.5 & 4.7 \\
\hline EU 27* & & 2732 & 2.9 & 3.0 & 2.9 \\
\hline Other Europe+Former Soviet & & 1688 & 1.8 & 1.9 & 1.7 \\
\hline Asia+Oceania & & 1019 & 1.1 & 1.2 & 1.0 \\
\hline Other & & 563 & 0.6 & 0.6 & 0.6 \\
\hline Educational level $n=87644$ & & & & $n=41309$ & $n=46335$ \\
\hline$<9$ years of compulsory school & & 45525 & 51.9 & 56.6 & 47.8 \\
\hline 9 years of compulsory school & & 5942 & 6.8 & 7.8 & 5.9 \\
\hline$\leq 2$ years of upper secondary school & & 20033 & 22.9 & 24.3 & 21.5 \\
\hline 3 years of upper secondary school & & 6889 & 7.9 & 3.0 & 12.2 \\
\hline$<3$ years of higher education & & 4215 & 4.8 & 4.0 & 5.5 \\
\hline$\geq 3$ years of higher education & & 5040 & 5.4 & 4.2 & 7.1 \\
\hline Employment status n=91 373 & & & & $n=43747$ & $n=47626$ \\
\hline Gainfully employed & & 5608 & 6.1 & 3.1 & 9.0 \\
\hline Sporadic gainful employment & & 6657 & 7.3 & 3.9 & 10.4 \\
\hline No gainful employment & & 79108 & 86.6 & 93.0 & 80.6 \\
\hline Income. mean (SD) n=91 373 & $€ 17412(28802)$ & & & $€ 15118$ (17 658) & $€ 19526$ (35 998) \\
\hline Income. median (IQR) & $€ 14222$ (6199) & & & & \\
\hline Income class (quartiles) & & & & $\mathrm{n}=43747$ & $\mathrm{n}=47626$ \\
\hline$\leq € 11884$ & & 22892 & 25.1 & 33.5 & 17.3 \\
\hline$€ 11$ 895-€14 222 & & 22872 & 25.0 & 31.6 & 19.0 \\
\hline$€ 14233-€ 18083$ & & 22777 & 24.9 & 21.2 & 28.4 \\
\hline$\geq € 18083$ & & 22832 & 25.0 & 13.7 & 35.3 \\
\hline Comorbidity. $n=93258$ & & & & $n=44619$ & $n=48639$ \\
\hline Hypertension & & 26117 & 28.0 & 30.7 & 25.6 \\
\hline Myocardial infarction (acute/previous) & & 14394 & 15.4 & 13.4 & 17.3 \\
\hline Kidney failure & & 7148 & 7.7 & 6.0 & 9.2 \\
\hline Diabetes mellitus & & 18059 & 19.4 & 17.9 & 20.7 \\
\hline Dementia & & 706 & 0.8 & 0.9 & 0.6 \\
\hline
\end{tabular}

*EU 27=Belgium, Denmark, France, Germany, Greece, Ireland, Italy, Luxembourg, The Netherlands, Portugal, Spain, UK, Austria, Finland, Sweden, Cyprus, Czech Republic, Estonia, Hungary, Latvia, Lithuania, Malta, Poland, Slovakia, Slovenia, Bulgaria, Romania.

\section{Comorbidity}

Hypertension was the most frequent comorbidity (28\%) and over-represented in women $(30.7 \%, \mathrm{p}<0.001)$, whereas men had more MI, kidney failure and DM (table 1). The frequency of DM (19.4\%) was similar to the proportion of patients dispensed diabetes drugs within 1 year $(19.8 \%)$.

\section{Treatment}

Overall, 51.1\% ( $\mathrm{n}=48$ 011) were dispensed an ACEI at least once within 1 year of HF hospitalisation and $20.5 \%$ received an ARB. Seventy per cent were hospitalised in internal medicine and $12.5 \%$ in cardiology departments.

\section{Analyses}

Comparisons of ACEI dispensations between groups (table 2) showed that men received an ACEI more often $(55.5 \%)$ than women $(47.5 \%, \mathrm{p}<0.001)$.
With higher age class, the proportion with ACEI dispensation decreased. Those without gainful employment received less ACEIs than those employed. ACEIs were dispensed more often to patients in the highest income group than those in the lowest income group.

Those with the lowest education were dispensed less ACEIs than those with the highest education.

Crude ORs showed a negative effect of female sex, older age, education $<9$ years, lower employment grade and lower income class on the risk of lack of an ACEI dispensation (table 3).

Adjusted ORs attenuated all crude effects and obliterated the effect of educational level. In the fully adjusted model, women were less likely to receive an ACEI (OR 1.31, (95\% CI 1.27 to 1.35). Age class also negatively affected ACEI dispensation, with a fully adjusted OR of 2.71 (95\% CI 2.53 to 2.91 ) in the oldest patients. Sporadically employed patients had an adjusted OR (model 4) of 1.37 (95\% CI 1.25 to 1.51) for lack of ACEI and the OR for unemployed patients was 1.59 (95\% CI 1.46 to 1.73 ). 
Table 2 Comparisons of ACEI dispensation between groups

\begin{tabular}{|c|c|c|}
\hline & $\begin{array}{l}\text { ACEI dispensation } \\
\leq 1 \text { year of } \\
\text { hospitalisation } \\
\text { for HF }(\%)\end{array}$ & $\mathrm{p}$ Value \\
\hline Sex, $n=93258$ & & $<0.001$ \\
\hline Women & 47.1 & \\
\hline Men & 55.5 & \\
\hline Age class (years), $n=93258$ & & $<0.001$ \\
\hline $20-64$ & 69.4 & \\
\hline $65-74$ & 60.9 & \\
\hline $75-84$ & 53.3 & \\
\hline$\geq 85$ & 40.3 & \\
\hline Country/region of birth, $n=93243$ & & $<0.001$ \\
\hline Sweden & 50.9 & \\
\hline Nordic country & 55.9 & \\
\hline EU $27^{*}$ & 53.4 & \\
\hline Other European countries+Former Soviet & 58.2 & \\
\hline Asia+Oceania & 60.9 & \\
\hline Other & 56.3 & \\
\hline Educational level, $n=87644$ & & $<0.001$ \\
\hline$<9$ years of compulsory school & 50.8 & \\
\hline 9 years of compulsory school & 55.8 & \\
\hline$\leq 2$ years of upper secondary school & 53.7 & \\
\hline 3 years of upper secondary school & 54.2 & \\
\hline$<3$ years of higher education & 55.0 & \\
\hline$\geq 3$ years of higher education & 54.9 & \\
\hline Employment status, $n=91373$ & & $<0.001$ \\
\hline Gainfully employed & 73.0 & \\
\hline Sporadic gainful employment & 58.0 & \\
\hline No gainful employment & 50.1 & \\
\hline Income class (quartiles), n=91 373 & & $<0.001$ \\
\hline$\leq € 11884$ & 51.1 & \\
\hline$€ 11895-€ 14222$ & 50.0 & \\
\hline$€ 14233-€ 18083$ & 51.9 & \\
\hline$\geq € 18083$ & 55.3 & \\
\hline
\end{tabular}

*EU $27=$ Belgium, Denmark, France, Germany, Greece, Ireland, Italy, Luxembourg, The Netherlands, Portugal, Spain, UK, Austria, Finland, Sweden, Cyprus, Czech Republic, Estonia, Hungary, Latvia, Lithuania, Malta, Poland, Slovakia, Slovenia, Bulgaria, Romania.

ACEl, ACE inhibitor; HF, heart failure.

Age-stratified analysis of the 20-64-year-old patients (ie, of working age) revealed an OR of 1.36 (95\% CI 1.14 to 1.62$)$ for lack of ACEI dispensation for sporadically employed patients, and 1.58 (95\% CI 1.40 to 1.77$)$ for those unemployed. Women had an adjusted OR of 1.73 (95\% CI 1.55 to 1.93) for not being dispensed an ACEI. In the age stratum 65 years and above, the corresponding ORs were 1.59 (CI 95\% 1.36 to 1.86 ) for the sporadically employed and 2.08 (95\% CI 1.79 to 2.41) for unemployed patients. For women, the OR was 1.39 (CI 1.34 to 1.43 ).

\section{DISCUSSION}

Our study suggested that access to ACEIs for patients with HF in Sweden is generally low as well as inequitable. We demonstrated that old age, unemployment and female sex were risk factors for not receiving treatment according to evidence-based guidelines.

\section{Treatment with ACEls}

We found that half of the study subjects had an ACEI dispensed. This is rather similar to other Swedish investigations in the past two decades. ${ }^{8-11}$ Yearly reports from the Swedish HF quality register 'RiksSvikt' show increasing RAS blockade use in recent years. In 2012, 69\% of patients with HF-PEF and $87 \%$ of those with HF-REF had RAS-blocking treatment. These findings indicate that RAS blockade treatment for HF-REF has improved, whereas it is still less used for HF-PEF, which may reflect the lack of evidence and guidelines regarding ACEIs in HF-PEF. ${ }^{27}$

\section{Equity}

Equity in health and healthcare has been systematically studied since the 1980s. ${ }^{28} 29$ There is a strong socioeconomic gradient in health, the risk of developing a number of diseases, as well as in disease outcome and mortality. ${ }^{30}$ Inequity in treatment and adherence to evidence-based guideline-recommended therapy, in cardiovascular as well as other medical fields, is well documented. ${ }^{31-33}$ This inequity in treatment may contribute to a poor disease outcome. Socioeconomically disadvantaged patients are thus at double risk, first of contracting disease and then of receiving suboptimal treatment.

Socioeconomic position is a strong predictor for HF according to a systematic review summarising 28 studies from several countries, including Sweden. ${ }^{12}$

\section{Socioeconomic position}

Low-socioeconomic position, represented in our study by low employment grade, was associated with a $30-50 \%$ increased risk of not being dispensed an ACEI (table 3). It appears as though the farther away from gainful employment, the greater the risk was for under-treatment, as reflected in the lower OR for sporadically employed versus unemployed patients. Although retirement pensioners can be assumed to fall into the unemployed group, there was still a unique effect of unemployment after age adjustment in the multivariate analysis. Additionally, the disadvantage of a lower employment grade was similar in the subgroup analysis of patients of working age. An interesting finding is that age-stratified analysis showed a negative effect (even stronger than in the younger stratum) of unemployment even in the age classes where a larger proportion would not be continuously employed. Conversely, this might be interpreted as a positive effect of some kind of employment, at a higher age, on access to ACEIs.

These findings are relevant because few studies have investigated ACEI access and socioeconomic status. One previous investigation in the UK found that ACEIs are more rare in socioeconomically deprived living areas. ${ }^{18}$

There was no negative effect on ACEI dispensation of educational level or income class in the adjusted models. The meaning of this finding is unclear, but one interpretation is that the social consequences of unemployment are more important in access to healthcare than are material resources or ability to access and understand medical information.

Sex

Female patients had a $30 \%$ higher risk of not being dispensed ACEIs (table 3), in line with previous studies. ${ }^{15}$ In the EuroHeart survey, women and older patients were less likely to receive ACEIs. ${ }^{8}$ Additionally, in Swedish primary care, women with HF were prescribed less ACEIs than men. ${ }^{10}$ A German HF study also disclosed a lower proportion of ACEIs provided to women than to men. ${ }^{14}$

A recent Swedish study found that women with ST-elevation MI (STEMI) had higher in-hospital mortality than men, and received less evidence-based therapies including ACEIs. ${ }^{16}$ Unadjusted 1-year mortality was higher in women, but the sex difference was reversed when adjusting for differences in 
Table 3 Multivariate logistic regression analysis of a lack of ACE inhibitor dispensation within 1 year of heart failure hospitalisation

\begin{tabular}{|c|c|c|c|c|}
\hline & Crude OR $(95 \% \mathrm{Cl})$ & $\begin{array}{l}\text { Model } 2 \\
\text { Adjusted for age } \\
\text { OR }(95 \% \mathrm{Cl})\end{array}$ & $\begin{array}{l}\text { Model } 3 \\
\text { Adjusted for age } \\
\text { and confounders } \\
\text { OR }(95 \% \mathrm{Cl})\end{array}$ & $\begin{array}{l}\text { Model } 4 \\
\text { Adjusted for age, confounders } \\
\text { and all other covariates } \\
\text { OR }(95 \% \mathrm{Cl})\end{array}$ \\
\hline \multicolumn{5}{|l|}{ Sex, n=93 258} \\
\hline Men & Ref & Ref & Ref & Ref \\
\hline Women & $1.40(1.37 \text { to } 1.44)^{* * *}$ & $1.20(1.17 \text { to } 1.23)^{* * *}$ & $1.29(1.25 \text { to } 1.33)^{* * *}$ & $1.31(1.27 \text { to } 1.35)^{* * *}$ \\
\hline \multicolumn{5}{|l|}{ Age class (years), $n=93258$} \\
\hline $20-64$ & Ref & & Ref & Ref \\
\hline $65-74$ & $1.46(1.38 \text { to } 1.54)^{* * *}$ & & $1.40(1.32 \text { to } 1.49)^{* * *}$ & $1.17(1.09 \text { to } 1.26)^{* * *}$ \\
\hline $75-84$ & $1.99(1.90 \text { to } 2.09)^{* * *}$ & & $1.97(1.86 \text { to } 2.07)^{* * *}$ & $1.59(1.49 \text { to } 1.70)^{* * *}$ \\
\hline$\geq 85$ & $3.36(3.20 \text { to } 3.52)^{* * *}$ & & $3.54(3.35 \text { to } 3.74)^{* * *}$ & $2.71(2.53 \text { to } 2.91)^{* * *}$ \\
\hline \multicolumn{5}{|l|}{ Country/region of birth, $n=93243$} \\
\hline Sweden & Ref & Ref & Ref & Ref \\
\hline Nordic country & $0.82(0.77 \text { to } 0.87)^{* * *}$ & $0.93(0.88 \text { to } 0.99)^{*}$ & 0.97 (0.91 to 1.04$)$ & 0.95 (0.89 to 1.02 ) \\
\hline EU 27† & $0.90(0.84 \text { to } 0.97)^{* * *}$ & $0.99(0.91$ to 1.06$)$ & 1.07 (0.98 to 1.17$)$ & 1.00 (0.91 to 1.10$)$ \\
\hline Other Europe+Former Soviet & $0.75(0.68 \text { to } 0.82)^{* * *}$ & $0.93(0.84$ to 1.03$)$ & 1.09 (0.97 to 1.22$)$ & 1.07 (0.92 to 1.22 ) \\
\hline Asia+Oceania & $0.66(0.59 \text { to } 0.75)^{* * *}$ & 0.91 (0.80 to 1.03$)$ & $1.03(0.89$ to 1.19$)$ & 0.95 (0.79 to 1.16$)$ \\
\hline Other & $0.80(0.68 \text { to } 0.95)^{*}$ & 1.02 (0.86 to 1.22$)$ & 1.11 (0.92 to 1.35$)$ & $1.02(0.82$ to 1.28$)$ \\
\hline \multicolumn{5}{|l|}{ Educational level, $n=87644$} \\
\hline$<9$ years of compulsory school & $1.18(1.11 \text { to } 1.25)^{* * *}$ & 0.98 (0.92 to 1.04$)$ & $1.00(0.93$ to 1.07$)$ & 0.98 (0.91 to 1.05$)$ \\
\hline 9 years of compulsory school & 0.96 (0.89 to 1.04$)$ & 1.00 (0.93 to 1.08$)$ & 1.07 (0.98 to 1.16$)$ & 1.01 (0.93 to 1.11$)$ \\
\hline$\leq 2$ years of upper secondary school & 1.05 (0.98 to 1.11$)$ & $1.03(0.97$ to 1.10$)$ & $1.05(0.98$ to 1.13$)$ & 1.01 (0.94 to 1.08$)$ \\
\hline 3 years of upper secondary school & $1.03(0.96$ to 1.11$)$ & $1.02(0.95$ to 1.10$)$ & $1.01(0.93$ to 1.10$)$ & 1.05 (0.96 to 1.14$)$ \\
\hline$<3$ years of higher education & 0.99 (0.92 to 1.08$)$ & $1.02(0.94$ to 1.11$)$ & $1.02(0.92$ to 1.12$)$ & 1.00 (0.91 to 1.10$)$ \\
\hline$\geq 3$ years of higher education & Ref & Ref & Ref & Ref \\
\hline \multicolumn{5}{|l|}{ Employment status, n=91 373} \\
\hline Gainfully employed & Ref & Ref & Ref & Ref \\
\hline Sporadic gainful employment & $1.96(1.82 \text { to } 2.12)^{* * *}$ & $1.32(1.21 \text { to } 1.43)^{* * *}$ & $1.31(1.19 \text { to } 1.45)^{* * *}$ & $1.37(1.25 \text { to } 1.51)^{* * *}$ \\
\hline No gainful employment & $2.70(2.54 \text { to } 2.87)^{\star * *}$ & $1.51(1.40 \text { to } 1.62)^{* * *}$ & $1.60(1.47 \text { to } 1.74)^{\star \star *}$ & $1.59(1.46 \text { to } 1.73)^{* * *}$ \\
\hline \multicolumn{5}{|l|}{ Income class (quartiles), n=91 373} \\
\hline$\leq € 11884$ & $1.19(1.14 \text { to } 1.23)^{* * *}$ & 1.04 (1.00 to 1.08$)$ & $1.02(0.98$ to 1.07$)$ & $0.89(0.85 \text { to } 0.94)^{* * *}$ \\
\hline$€ 11895-€ 14222$ & $1.24(1.19 \text { to } 1.28)^{* * *}$ & 1.01 (0.97 to 1.05$)$ & 1.04 (0.99 to 1.08$)$ & $0.91(0.87 \text { to } 0.96)^{* * *}$ \\
\hline$€ 14233-€ 18083$ & $1.15(1.11 \text { to } 1.19)^{* * *}$ & $1.00(0.96$ to 1.04$)$ & 1.04 (1.00 to 1.08$)$ & 0.98 (0.94 to 1.02$)$ \\
\hline$\geq € 18083$ & Ref & Ref & Ref & Ref \\
\hline
\end{tabular}

Model 2: ORs were adjusted for age; model 3: ORs were adjusted for age and comorbidity, ARB dispensation, year and days of follow-up; model 4: model 3+all covariates. ${ }^{* * *} p<0.001 ;{ }^{* *} p<0.01 ;{ }^{*} p<0.005$.

TEU $27=$ Belgium, Denmark, France, Germany, Greece, Ireland, Italy, Luxembourg, The Netherlands, Portugal, Spain, UK, Austria, Finland, Sweden, Cyprus, Czech Republic, Estonia, Hungary, Latvia, Lithuania, Malta, Poland, Slovakia, Slovenia, Bulgaria, Romania.

$A R B$, angiotensin receptor blocker.

evidence-based treatment, indicating that this factor is important in early STEMI mortality. ${ }^{16}$ Aggregated cross-sectional drug dispensation data also showed a relative risk of 0.7 for women to be dispensed ACEIs compared with men. ${ }^{17}$

Many previous ACEI studies did not address ARB prescription as an explanation for women receiving less ACEIs than men. Women are more prone to adverse effects from ACEIs, ${ }^{34}$ so physicians may switch more women to treatment with ARBs, in accordance with guidelines. In our study, adjusting for ARB dispensation did not explain the sex difference, in accordance with a previous Swedish investigation. ${ }^{17}$

In the 20-64-years subgroup analysis, women had an even higher risk compared with men of not being dispensed an ACEI (adjusted OR 1.73 (95\% CI 1.55 to 1.93)). This finding is in line with a previous one that young females with STEMI fare worse than young men with respect to ACEI treatment and mortality. ${ }^{16}$ This possibly reflects a failure to recognise and accurately treat heart disease in this patient group because of a belief that cardiovascular illness does not affect young women. In addition, women compared to the men in our study had in general lower employment grade, less education and less income, indicating that Swedish female patients with HF have an aggregation of negative socioeconomic circumstances.

\section{Country of birth}

There was no disadvantage in ACEI access associated with country of birth. Our study may be underpowered for detecting such differences because groups of foreign-born patients were small. However, a Swedish study of patients with HF in 1994-2003 also found treatment for foreign-born patients to be equitable. ${ }^{35}$ In contrast, another investigation found less ACEI prescriptions after acute MI for foreign born than for Swedish patients. ${ }^{19}$

Immigrants are assuredly not a homogeneous group. Any categorisation by country or region of birth will be somewhat inadequate in capturing common problems for 'immigrants' in access to care or health. The risks of discrimination, as well as social segregation and socioeconomic challenges, vary between immigrant groups. A study by Hollander et a ${ }^{36}$ concluded, for example, that cardiovascular mortality is higher among refugee versus non-refugee immigrants. Several other studies have 
demonstrated low access to healthcare for immigrants. ${ }^{37}$ In our study, however, the inclusion criterion was that patients be hospitalised for $\mathrm{HF}$, meaning that the foreign-born patients under study are a selection of immigrants who have already achieved some access to healthcare.

Age

Age was a strong independent predictor for not being dispensed an ACEI in our study, (OR 2.71 (95\% CI 2.53 to 2.91)). This is noteworthy, as ACEI treatment reduces HF symptoms, which benefits all patients, regardless of life expectancy. Adjusting for comorbidity did not eradicate the effect of age, which implies inequitable treatment of older patients, in accordance with previous investigations. ${ }^{8}$

\section{Strengths and limitations}

The individually linked register data in this study are vast and detailed. Consequently, this material permits multifaceted analyses of drug dispensation in relation to multiple sociodemographic factors. Several possible confounding factors were included in the analyses to minimise systematic errors. Furthermore, the inpatient register is nearly a total register with almost $100 \%$ of hospitalisations registered. This gives our study high power and excellent generalisability for hospitalised patients. Nonetheless, there are some potential methodological limitations to our study.

We could not identify whether patients had preserved or reduced ejection fraction because ICD codes do not distinguish between these two types of HF. Consequently, interpreting adherence to evidence-based, guideline-recommended therapy for HF-PEF is difficult as recommendations are not clear on this point. In addition, women more often than men have HF-PEF, ${ }^{38}$ which adds complexity. However, in the 'RiksSvikt' report, ${ }^{27}$ even within the HF-PEF group, men receive RAS blockade to a higher extent than women. Furthermore, although more studies are required to confirm such a result, a mortality analysis of the 'RiksSvikt' population showed significantly better survival for patients with HF-PEF with ACEI treatment than for those without ACEI treatment. ${ }^{39}$ In summary, although our result that women received less ACEIs is difficult to interpret, there is still reason for concern that women, especially those $<65$ years of age, may be undertreated.

The outcome being defined as a lack of an ACEI dispensation within 1 year of hospitalisation could influence the interpretation of inequity in access to ACEI. Patients might die before having the chance to collect a prescribed ACEI, which is more likely to happen for the sickest and oldest patients. We have handled this risk by adjusting for comorbidities, as well as for days of follow-up in the regression models. Hence, we do not believe this substantially influenced our results.

Dispensation of a drug is a proxy for receiving a prescription. Different patient adherence could thus lead to bias in interpreting our results as inequitable treatment. However, nonadherence to a prescription may reflect inequality in healthcare based on patients' capacity to receive and understand medical information, their motivation towards health, or financial and physical ability to acquire prescribed drugs. In our study, women generally had a lower income than men. According to the Swedish public health survey in $2013,25 \%$ of women and $15 \%$ of men refrain from collecting prescribed drugs due to lack of money. ${ }^{40}$ It is thus possible that female, unemployed or old patients in our study were less adherent to prescribed ACEIs. Nonetheless, reduced access to RAS blockade for these patients is relevant from an equity view.

\section{CONCLUSION}

We demonstrated differences in ACEI treatment among Swedish patients hospitalised for HF. Access to ACEI treatment was reduced in women, and in patients of higher age and lower employment status. In contrast, there was no inequity based on country of birth, educational level or income. Although reasons for these differences in ACEI treatment are not completely elucidated, we conclude that ACEI access is inequitable among Swedish patients with HF.

The principal goal in the Swedish health and medical services act is to achieve good and equal healthcare for all Swedish citizens. To this end, mechanisms of inequity in health and healthcare need to be further investigated. In future studies, we plan to combine clinical data with our register data for more elaborate analyses, taking into account ejection fraction and actual prescribing. These studies should include mortality analysis in different patient groups with HF.

\section{What is already known on this subject?}

Good health and access to healthcare are not equally distributed in the population. There is sex and age inequity in access to evidence-based treatment, such as ACE inhibitors in heart failure. Some evidence also points to reduced access for patients with low socioeconomic position.

\section{What do this study add?}

- This study investigates unequal ACE inhibitor (ACEI) access based on sex, age, country of birth, education, employment and income in a large individually linked register population.

- We found inequity in access to ACEI in women, older patients and unemployed patients with heart failure. The reasons for not receiving ACEI treatment are unclear, and more background as well as diagnostic and prescription data is needed to elucidate this subject.

- The inequity in treatment may influence outcome, including mortality, which will be investigated in forthcoming studies.

\section{Policy implications}

- The findings could have implications for intensifying efforts to provide equitable healthcare.

- Areas of focus could be: stronger implementation of adherence to evidence-based treatment guidelines as well as increasing awareness about gender and equality issues, and mechanisms involved in patient management and decision-making.

Contributors RW has contributed to the conception and design of the research, analysis and interpretation of the data, drafting of the manuscript, critical revision of the manuscript for important intellectual content and supervision. BL contributed to the conception and design of the research, analysis and interpretation of the data, critical revision of the manuscript for important intellectual content and supervision. $\mathrm{MH}$ contributed to the conception and design of the research, critical revision of the 
manuscript for important intellectual content and supervision. All the authors have seen and approved the final version of the manuscript and agree to be accountable for all aspects of the work in ensuring that questions related to the accuracy or integrity of any part of the work are appropriately investigated and resolved.

Funding This work was supported by grants from the Uppsala Academic hospital ('ALF'-grant 2011 and 2014).

Competing interests None declared.

Ethics approval The Swedish Central Ethical Review Board.

Provenance and peer review Not commissioned; externally peer reviewed.

Open Access This is an Open Access article distributed in accordance with the Creative Commons Attribution Non Commercial (CC BY-NC 4.0) license, which permits others to distribute, remix, adapt, build upon this work non-commercially, and license their derivative works on different terms, provided the original work is properly cited and the use is non-commercial. See: http://creativecommons.org/ licenses/by-nc/4.0/

\section{REFERENCES}

1 Zarrinkoub R, Wettermark B, Wandell P, et al. The epidemiology of heart failure, based on data for 2.1 million inhabitants in Sweden. Eur I Heart Fail 2013:15:995-1002.

2 Paren P, Schaufelberger M, Bjorck L, et al. Trends in prevalence from 1990 to 2007 of patients hospitalized with heart failure in Sweden. Eur I Heart Fail 2014; 16:737-42.

3 The CONSENSUS Trial Study Group. CONSENSUS. Effects of enalapril on mortality in severe congestive heart failure. Results of the Cooperative North Scandinavian Enalapril Survival Study (CONSENSUS). N Engl I Med 1987;316:1429-35.

4 The SOLVD investigators. Effect of enalapril on survival in patients with reduced left ventricular ejection fractions and congestive heart failure. $N$ Engl I Med 1991:325:293-302.

5 Ball SG, Hall AS, Mackintosh AF, et al. Effect of ramipril and morbidity of survivors of acute myocardial infarction with clinical evidence of heart failure. Lancet 1993;342:821-8

6 Agarwal V, Briasoulis A, Messerli FH. Effects of renin-angiotensin system blockade on mortality and hospitalization in heart failure with preserved ejection fraction. Heart Fail Rev 2013;18:429-37.

7 McMurray JJ, Adamopoulos S, Anker SD, et al. ESC guidelines for the diagnosis and treatment of acute and chronic heart failure 2012: the Task Force for the Diagnosis and Treatment of Acute and Chronic Heart Failure 2012 of the European Society of Cardiology. Developed in collaboration with the Heart Failure Association (HFA) of the ESC. Eur J Heart Fail 2012;14:803-69.

8 Komajda M, Follath F, Swedberg K, et al. The EuroHeart Failure Survey programme - a survey on the quality of care among patients with heart failure in Europe. Part 2: treatment. Eur Heart I 2003;24:464-74.

9 de Peuter ORL, Souverein GY, Klungel PC, et al. Time-trends in treatment and cardiovascular events in patients with heart failure: a pharmacosurveillance study. Eur J Heart Fail 2011;13:489-95.

10 Agvall B, Dahlström U. Patients in primary health care diagnosed and treated as heart failure, with special reference to gender differences. Scand I Prim Health Care 2001:19:14-19.

11 Dahlstrom U, Hakansson J, Swedberg K, et al. Adequacy of diagnosis and treatment of chronic heart failure in primary health care in Sweden. Eur I Heart Fail 2009;11:92-8

12 Hawkins NM, Jhund PS, McMurray JJV, et al. Heart failure and socioeconomic status: Accumulating evidence of inequality. Eur J Heart Fail 2012;14:138-46.

13 Schaufelberger $M$, Rosengren A. Heart failure in different occupational classes in Sweden. Eur Heart I 2007;28:212-18.

14 Baumhakel M, Muller U, Bohm M. Influence of gender of physicians and patients on guideline-recommended treatment of chronic heart failure in a cross-sectional study. Eur J Heart Fail 2009;11:299-303.

15 McSweeney J, Pettey C, Lefler $\mathrm{LL}$, et al. Disparities in heart failure and other cardiovascular diseases among women. Womens Health 2012;8:473-85.

16 Lawesson SS, Alfredsson J, Fredrikson $\mathrm{M}$, et al. A gender perspective on short- and long term mortality in ST-elevation myocardial infarction -A report from the SWEDEHEART register. Int J Cardiol 2013;168:1041-7.
17 Loikas D, Wettermark B, von Euler $\mathrm{M}$, et al. Differences in drug utilisation between men and women: a cross-sectional analysis of all dispensed drugs in Sweden. BMJ Open 2013;3:pii: e002378

18 Ward PR, Noyce PR, St Leger AS. Exploring the equity of GP practice prescribing rates for selected coronary heart disease drugs: a multiple regression analysis with proxies of healthcare need. Int J Equity Health 2005;4:3.

19 Ringback Weitoft $\mathrm{G}$, Ericsson $\mathrm{O}$, Lofroth $\mathrm{E}$, et al. Equal access to treatment? Population-based follow-up of drugs dispensed to patients after acute myocardial infarction in Sweden. Eur I Clin Pharmacol 2008;64:417-24.

20 Mathur R, Badrick E, Boomla K, et al. Prescribing in general practice for people with coronary heart disease; equity by age, sex, ethnic group and deprivation. Ethn Health 2011;16:107-23.

21 Swedish National board of health and welfare. Swedish national inpatient register. Secondary Swedish national inpatient register [Web page]. http://www. socialstyrelsen.se/register/halsodataregister/patientregistret.swedish

22 Ludvigsson JF, Andersson E, Ekbom A, et al. External review and validation of the Swedish national inpatient register. BMC Public Health 2011;11:450.

23 Ingelsson E, Arnlov J, Sundstrom J, et al. The validity of a diagnosis of heart failure in a hospital discharge register. Eur J Heart Fail 2005;7:787-91.

24 Swedish National board of health and social welfare. Swedish prescribed drug register. Secondary Swedish prescribed drug register [Web page]. http://www. socialstyrelsen.se/register/halsodataregister/lakemedelsregistret.swedish

25 Wettermark B, Hammar N, Fored CM, et al. The new Swedish Prescribed Drug Register-opportunities for pharmacoepidemiological research and experience from the first six months. Pharmacoepidemiol Drug Saf 2007:16:726-35.

26 Statistics Sweden (SCB). LISA database. Secondary LISA database. [Web page]. http://www.scb.se/en_/Services/Guidance-for-researchers-and-universities/SCB-Data/ Longitudinal-integration-database-for-health-insurance-and-labour-market-studiesLISA-by-Swedish-acronym/.eng; http://www.scb.se/lisa/swedish

27 Dahlström U VP, Jonsson Å. Yearly report 2012, SwedeHF register. [Årsrapport RiksSvikt 2012 års resultat] 2013. http://www.ucr.uu.se/rikssvikt-en/index.php/ quality-registry/about-swedehf

28 Krasnik A. The concept of equity in health services research. Scand I Soc Med 1995;24:2-7.

29 Mooney G. What does equity in health mean? World Health Stat Q 1987;40:296

30 Westerling R, Gullberg A, Rosen M. Socioeconomic differences in 'avoidable' mortality in Sweden 1986-1990. Int J Epidemiol 1996;25:560-7.

31 Mattsson P, Tomson T, Edebol Eeg-Olofsson K, et al. Association between sociodemographic status and antiepileptic drug prescriptions in children with epilepsy. Epilepsia 2012;53:2149-55.

32 Haider SI, Johnell K, Ringback Weitoft G, et al. Patient educational level and use of newly marketed drugs: a register-based study of over 600,000 older people. Eur J Clin Pharmacol 2008;64:1215-22.

33 Olsson LI, Granstrom F, Glimelius B. Socioeconomic inequalities in the use of radiotherapy for rectal cancer: a nationwide study. Eur J Cancer 2011;47:347-53.

34 Mackay FJ, Pearce GL, Mann RD. Cough and angiotensin II receptor antagonists: cause or confounding? Br J Clin Pharmacol 1999;47:111-14.

35 Hedemalm A, Schaufelberger M, Ekman I. Equality in the care and treatment of immigrants and native Swedes-a comparative study of patients hospitalised for heart failure. Eur I Cardiovasc Nurs 2008;7:222-8.

36 Hollander AC, Bruce D, Ekberg J, et al. Longitudinal study of mortality among refugees in Sweden. Int J Epidemiol 2012;41:1153-61.

37 Westin M, Ahs A, Brand Persson K, et al. A large proportion of Swedish citizens refrain from seeking medical care-lack of confidence in the medical services a plausible explanation? Health Policy 2004;68:333-44.

38 Steinberg BA, Zhao X, Heidenreich PA, et al. Trends in patients hospitalized with heart failure and preserved left ventricular ejection fraction: prevalence, therapies, and outcomes. Circulation 2012;126:65-75.

39 Lund LH, Benson L, Dahlstrom U, et al. Association between use of reninangiotensin system antagonists and mortality in patients with heart failure and preserved ejection fraction. JAMA 2012:308:2108-17.

40 Public health Agency of Sweden. Swedish public health survey [Nationella folkhälsoenkäten "Hälsa på lika villkor]". 2013. http://www.folkhalsomyndigheten. se/amnesomraden/statistik-och-undersokningar/enkater-och-undersokningar/ nationella-folkhalsoenkaten/ 